\title{
Gibson, Picraux, and Scheetz to Chair 1987 MRS Fall Meeting
}

\author{
21 Symposia, Complementary Short Course Program Planned
}

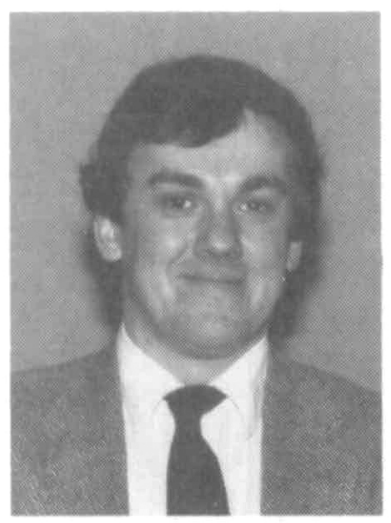

J.M. Gibson

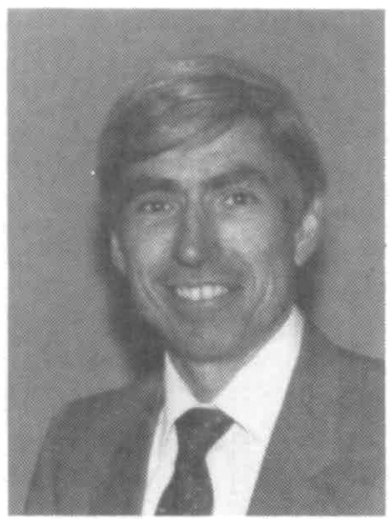

S.T. Picraux

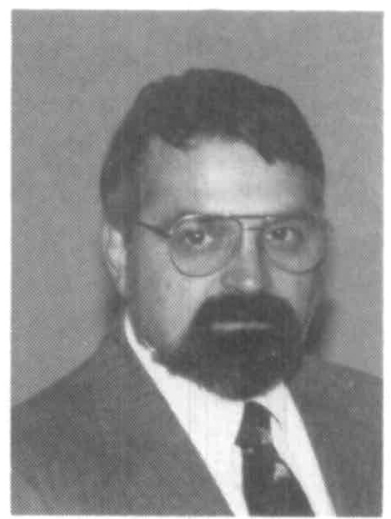

B.E. Scheetz
J. Murray Gibson, S. Thomas Picraux, and Barry E. Scheetz have been appointed Meeting Chairs for the 1987 MRS Fall Meeting, scheduled for the week of November 30-December 5, 1987 in Boston, Massachusetts. The 21 technical symposia planned will emphasize the meeting's traditional wide coverage of key materials areas with a strong emphasis on the interdisciplinary approach. A balance between mainstream areas and fast-breaking new activities is anticipated.

Murray Gibson is a member of the technical staff in the Interface Physics Department at AT\&T Bell Laboratories, Murray Hill, NJ. He holds a PhD in physics from the University of Cambridge (1978) and has also worked briefly at IBM's T.J. Watson Research Center. His current field of research is high resolution electron $\mathrm{mi}$ croscopy of interfaces and surfaces in electronic materials. He has published over 100 papers and edited two volumes in the MRS Symposia Proceedings series. He has a strong scientific interest in epitaxial heterostructures and has organized two MRS symposia on the subject. He is co-organizer of the symposium on Initial Stages of Epitaxial Growth at the 1987 MRS Spring Meeting.

"I hope the 1987 Fall Meeting will continue in the excellent MRS tradition. With the rapid growth of the Society's activities we must not forget the importance of the scientific content of the Fall Meeting to our existence today and in the future. We have tried to respond to often heard criticisms of the meeting by limiting the number of symposia and avoiding excessive overlap in topics."

Tom Picraux is manager of the Ion Implantation and Radiation Physics Research Department at Sandia National Laborato- ries, Albuquerque, NM. He joined the Sandia technical staff in 1969 and since then has also held the position of supervisor, Ion Solid Interactions Division. In addition to his involvement with MRS, he is a member of IEEE, the Electrochemical Society, The Metallurgical Society, and is a Fellow of the American Physical Society. He was symposium organizer of the symposium on Beam-Solid Interactions and Transient Processes at the 1986 MRS Fall Meeting, and in 1985 served on the $\mathrm{Na}$ tional Academy of Sciences' Materials Science Briefing Panel. He holds a BS in electrical engineering from the University of Missouri, and an MS and PhD in engineering science and physics, both from the California Institute of Technology.

Barry Scheetz is associate professor of solid-state science and senior research associate at the Materials Research Laboratory at Pennsylvania State University, where he has been a faculty member for ten years. He received his undergraduate degree in education from Bloomsburg State College and his $\mathrm{PhD}$ in geochemistry and mineralogy from Pennsylvania State University. He works and publishes extensively in the area of nuclear and hazardous chemical waste management. His principal areas of interest are waste form development and waste form chemistry associated with both nuclear and hazardous waste systems; and he is involved with their applications in nuclear waste repositories and cementitious-based waste forms.

Symposia planned for the Fall Meeting are:

Fundamentals of Beam-Solid Interactions and Transient Thermal Processing

Laser and Particle-Beam Chemical Processing for Microelectronics
Epitaxy of Semiconductor Layered Structures

Multilayers: Synthesis, Properties, and Nonelectronic Applications

Defects in Electronic Materials

$\mathrm{SiO}_{2}$ and Its Interfaces

Polysilicon Films and Interfaces

Silicon-on-Insulators and Buried Metals in Semiconductors

Electronic Packaging Materials Science

Structure-Property Relationships in Optical Materials

Nonlinear Optical Properties of Polymers

Polymer Surfaces, Interfaces, and Adhesion

Biomedical Materials and Devices

Plasma-Assisted Deposition of New Materials

Microstructure and Properties of Catalysts Scientific Basis for Nuclear Waste Disposal XI

Fly Ash and Coal Conversion By-Products: Characterization, Utilization, and Disposal IV

Bonding in Cementitious Composites

Fractals and Disordered Materials

Workshop on Specimen Preparation for Transmission Electron Microscopy of Materials

Frontiers in Materials Science

Education in Materials Science and Engineering: The Changing Role of University, Industry, and Government Interactions

Symposium $X$, Frontiers in Materials Education will also be offered as a lunchtime forum, and a short course program featuring complementary topics is also planned. See upcoming issues of the MRS BULLETIN for details on the program.

MRS 


\title{
BIOMEDICAL MATERIALS
}

\author{
Volume 55 \\ Edited by J.M. Williams, M.F. Nichols, and W. Zingg
}

New materials processing techniques and methods of analysis have equipped the materials scientist/ engineer as never before to respond to the unique challenges posed by in-vivo applications of materials. The first MRS symposium on biomedical materials brought together an international interdisciplinary group of experts to discuss developments in materials affecting the broad range of bioengineering practices around the world. The meeting emphasized developments in orthopaedics, electronic materials, and basic science and technology of biomaterials.

The proceedings contains 43 papers contibuted by scientists from the United States, Canada, China, France, Germany, Sweden, Switzerland, and UK. Topics include:

\section{Orthopaedics}

Ultrahigh molecular weight polyethylene in joint compounds - cemented UHMWPE total hip acetabular cups - use of $\mathrm{BMP}$ and cancellous graft for porous surfaced interface voids $-\mathrm{Al}_{2} \mathrm{O}_{3}$ fatigue fracture of ceramic-to-ceramic total hip replacements - improved ion implanted Ti-6 Al-4V alloy for implants - nitrogen ion-implantation on the abrasive wear resistance of Ti-6Al-4V/UHMWPE couple

\section{Biomaterials for Electrodes}

Bioelectrodes for neuroprostheses - conductive polymer electrodes for neuroprotheses - stimulated electrodes based on $\mathrm{MnO}_{2}$ thin films - insulating polyphenylene oxide films on platinum electrodes - electronic materials for biological application

\section{Science and Technology of Biomaterials}

Chemical composition and morphology of titanium surface oxides - semi-solid processing of titanium alloys - fracture loughness testing of in-vivo aged biomaterials - microstructure, wear and friction of ion beam-induced amorphous Ti/Pd alloys - surface spectroscopic studies of solution cast biomedical grade polymer mixtures

\section{Cardiovascular Materials}

Small diameter vascular graft - failure of arterial prostheses - blood compatibility problems - calcium and magnesium with HEMA/MAA

\section{Opthalmic Biomaterials}

Biomaterials in opthalmology: a generalist's overview - materials for retinal detachment

\section{Reconstruction Materials for Bones and Teeth}

Composite plaster/hydroxylapatite intraosseous implants - slow crack growth in dental composites - reconstructive surgery of craniomaxillofacial deformation with osteomesh

\section{Special Materials and Techniques}

Artificially induced biological organs - charged polymers as osmotic agents for peritoneal dialysis - spectroscopic ellipsometry studies of Giaever immunology slides - light and scanning electron microscopy for human spinal ligaments

\section{Simulation and Practice}

Plasma proteins in corrosion of $316 \mathrm{~L}$ stainless steel in vitro - stress corrosion cracking of stainless steel threaded fixation (Steinmann) pins for vertebral body stabilization - capsular contracture around PDMS and PE implants

$$
\text { Hardbound, illustrated ISBN: 0-931837-20-0 }
$$

MRS Members $-\$ 37.00 \quad$ U.S. Nonmembers $-\$ 46.00 \quad$ Foreign Nonmembers-- $\$ 51.00$

\footnotetext{
Order from: Publications Department, Materials Research Society, 9800 McKnight Road, Suite 327, Pittsburgh, PA 15237; telephone (412) 367-3012

Prepayment required. VISA and Master Card accepted.
} 